\title{
Evaluating and treating neurobehavioral symptoms in professional American football players: Lessons from a case series
}

Nitin K. Sethi, MD: I read with interest the Gardner et al. ${ }^{1}$ study on retired professional American football players. Their study highlights the complexity of diagnosing chronic traumatic encephalopathy (CTE) with certainty in this patient population. Though seemingly homogenous, this group of retired professional American football players are heterogeneous with respect to number of games played; number of documented and undocumented concussive and subconcussive injuries; presence or absence of vascular risk factors such as hypertension, diabetes, dyslipidemia, and smoking history; baseline cognitive reserve; presence or absence of depression and anxiety disorder; lifestyle factors such as diet and exercise; family history of Alzheimer disease; and $A P O E$ status. In the absence of a reliable biological fluid or imaging biomarker for concussion (let alone for CTE), a physician must exercise extreme caution when evaluating a symptomatic active or retired professional athlete presenting with cognitive and neurobehavioral complaints. As things stand now, our diagnosis is at best an educated guess.

New York-Presbyterian Hospital.

Disclosures: N. Sethi serves as Associate Editor for The Eastern Journal of Medicine.

Correspondence to: sethinitinmd@hotmail.com

Authors Respond: Raquel C. Gardner, MD, Gil D. Rabinovici, MD: We thank Dr. Sethi for his comment. As hypothesized in our discussion, ${ }^{1}$ the phenotypic heterogeneity observed in our case series may be explained in part by the varied exposure and susceptibility factors highlighted by Dr. Sethi. Furthermore, while some symptomatic former players may harbor CTE neuropathology, this condition can currently only be diagnosed postmortem. We agree that caution is warranted when diagnosing the cause of neurobehavioral impairment in lieu of validated biomarkers, though the uncertainty of clinical diagnosis is not unique to retired American football players, as illustrated by the not infrequent mismatch between clinical and neuropathologic diagnoses in Alzheimer disease and other neurodegenerative dementias. ${ }^{2}$ A variety of clinical, genetic, imaging, and molecular biomarkers are under active investigation in individuals exposed to repeated mild traumatic brain injury (mTBI), ${ }^{3}$ representing a critical first step towards refining diagnosis in preparation for therapeutic trials. However, regardless of the underlying pathology, it is imperative that as clinicians we recognize the very real neurologic disability experienced by these and other patients exposed to repeated mTBI. We strongly encourage providers to perform a thorough evaluation in individuals at risk for CTE, provide the best possible diagnosis and prognosis, and aggressively treat symptoms whenever possible.

University of California, San Francisco (R.C.G., G.D.R.), and San Francisco Veterans Affairs Medical Center (R.C.G.). Disclosures: R.C. Gardner has received funding for travel from the American Academy of Neurology and the Alzheimer's Association and has received research support from the Department of Veterans Affairs, NIH/NIA, and UCSF Pepper Center Research Career Development Core. G.D. Rabinovici has received funding for travel and/or speaker honoraria from Alzheimer's Association, GE Healthcare, Rockpointe, Tau Consortium, and Medscape and receives research support from Avid Radiopharmaceuticals/Eli Lilly, NIH/NIA, Alzheimer's Association, John Douglas French Alzheimer's Foundation, Hellman Family Foundation, and Tau Consortium.

Correspondence to: raquel.gardner@ucsf.edu

1. Gardner RC, Possin KL, Hess CP, et al. Evaluating and treating neurobehavioral symptoms in professional American football players: lessons from a case series. Neurol Clin Pract 2015;5:285-295. 
2. Beach TG, Monsell SE, Phillips LE, Kukull W. Accuracy of the clinical diagnosis of Alzheimer disease at National Institute on Aging Alzheimer Disease Centers, 2005-2010. J Neuropathol Exp Neurol 2012;71:266-273.

3. Riley DO, Robbins CA, Cantu RC, Stern RA. Chronic traumatic encephalopathy: contributions from the Boston University Center for the Study of Traumatic Encephalopathy. Brain Inj 2015;29:154-163.

\section{The feasibility of establishing a free clinic for uninsured patients with neurologic disorders}

Khichar Shubhakaran, MD: The article on free neurologic services for uninsured people by Taylor et al. ${ }^{1}$ was encouraging and in alignment with services we have provided in India for more than a decade. Providing free medical services, especially to those who have limited economic resources, is a novel act of humanity in these modern times. Free medical services have always been available in India for needy or poor patients but are much better organized now. A large percentage of the population was impoverished because of health-related expenses. ${ }^{2}$ Initially there was provision of free medical services to those below the poverty line, including neuroimaging and costly medicines like IV immunoglobulin, but now free medicine is supplied to every patient in government-run hospitals. Patients with neurologic disorders are referred to more specialized centers for diagnostic tests and treatment. Once enrolled, such patients keep on receiving regular treatment and follow-up at the medical college hospitals. Almost every medical college has a neurology center. Free services are also now available in certain private hospitals for patients below the poverty line. While lifting the burden of medical bills from the backs of patients is moving in a positive direction, ${ }^{3}$ much additional work is needed. ${ }^{4}$

Dr. S.N. Medical College, Jodhpur, India.

Disclosures: The author reports no disclosures.

Correspondence to: drkhicharsk@gmail.com

1. Taylor JJ, Larrew T, Omole A, et al. The feasibility of establishing a free clinic for uninsured patients with neurologic disorders. Neurol Clin Pract 2015;5:302-308.

2. Medical bills pushing Indians below poverty line: WHO. India Today Online 2011. Available at: http:// indiatoday.intoday.in/story/medical-bills-pushing-indians-below-poverty-line-who/1/158347.html. Accessed August 29, 2015.

3. Sood N, Bendavid E, Mukherji A, Wagner Z, Nagpal S, Mullen P. Government health insurance for people below poverty line in India: quasi-experimental evaluation of insurance and health outcomes. BMJ 2014;349:g5114.

4. Shukla R. Healthcare spend pushing households below poverty line: policy-makers need to look at healthcare as a key element of the economic well-being of the country. Financial Times 2015. Available at: http://www.financialexpress.com/article/fe-columnist/healthcare-spend-pushing-households-belowpoverty-line/126656/. Accessed August 29, 2015.

\section{Evaluating persistent altered mental status after status epilepticus}

Nitin K. Sethi, MD: I read with interest the case report by Newey et al. ${ }^{1}$ At the time of admission, EEG showed left hemispheric periodic lateralized epileptiform discharges (PLEDs) and left temporal seizures. By the time the ${ }^{18} \mathrm{~F}-\mathrm{FDG}$ PET was carried out (13 days after admission), EEG still showed PLEDs (maximally left temporal). The clinical significance of PLEDs has been debated in literature and current thinking is that they lie on the interictal to ictal continuum. In the authors' reported patient, the EEG phenomenon of PLEDs should be considered a part of the ongoing status epilepticus condition; hence I disagree with their comment that their patient's 
status epilepticus had resolved after treatment with 4 antiepileptic drugs. The FDG-PET scan showing left lateral and mesial temporal hypermetabolism is also consistent with an ictal PET. The significance of P/Q calcium channel antibodies in their patient is hence debatable.

New York-Presbyterian Hospital.

Disclosures: N. Sethi serves as Associate Editor for The Eastern Journal of Medicine.

Correspondence to: sethinitinmd@hotmail.com

Author Responds: Stephen Hantus, MD: Status epilepticus can manifest as a periodic pattern as it resolves or continues as described classically by Treiman. ${ }^{2}$ Our case ${ }^{1}$ had evolving seizures that stopped with antiepileptic drugs (at least that was our perception) with interictal PLEDs remaining. However, there was no clinical improvement. I agree with Dr. Sethi that the FDG-PET suggests ongoing ictal activity that raises the possibility of limbic encephalitis. Only after treating the patient with immunomodulating agents (steroids, IV immunoglobulin) did the patient improve. Finding later that the patient had the P/Q channel antibodies only confirmed what we discovered clinically. Without thinking of limbic encephalitis and immunomodulation, this status epilepticus would not have been successfully treated.

Cleveland Clinic Foundation, OH.

Disclosures: S. Hantus has served as a consultant and is on advisory boards for UCB Pharma.

Correspondence to: hantuss@ccf.org

1. Newey CR, George P, Hantus S. Evaluating persistent altered mental status after status epilepticus. Neurol Clin Pract 2015;5:534-535.

2. Treiman DM, Meyers PD, Walton NY. A comparison of four treatments for generalized convulsive status epilepticus. N Engl J Med 1998;339:792-798.

\section{The application of optical coherence tomography in neurologic diseases}

Khichar Shubhakaran, MD: I read with interest the review on optical coherence tomography (OCT) in various neurologic diseases by Maldonado et al. ${ }^{1}$ OCT is used extensively for clinical decision-making and monitoring of many posterior segment diseases based on macular, optic nerve, and retinal nerve fiber layer (RNFL) imaging. ${ }^{2}$ It is a noninvasive imaging technique and provides high-resolution, cross-sectional images of the retina, the RNFL, and the optic nerve head. ${ }^{2}$ I would like to draw particular attention to another important role OCT can play. ${ }^{3}$ OCT can aid with diagnosis, exclusion of diagnosis, and precipitation of angle closure glaucoma with topiramate use. ${ }^{4}$ Topiramate is used frequently in various neuropsychiatric conditions and is proving to be a promising drug (relatively inexpensive and with a low side effect profile). With better definition of optic nerve pathology, OCT will prove a useful tool to monitor and avoid topiramate side effects. ${ }^{4}$

Dr. S.N. Medical College, Jodhpur, India.

Disclosures: The author reports no disclosures.

Correspondence to: drkhicharsk@gmail.com

Authors Respond: M. Tariq Bhatti, MD, Ramiro S. Maldonado, MD, Pradeep Mettu, MD, Mays El-Dairi, MD: We would like to thank Dr. Shubhakaran for his insightful comments regarding our review article on the application of OCT in neurologic diseases. ${ }^{1}$ Topiramate is often used for a variety of neurologic diseases including migraines, bipolar disorder, epileptic seizures, and infantile spasms. From a pathomechanistic perspective, topiramate-induced glaucoma is due to ciliochoroidal effusion resulting in forward displacement of the iris-lens 
diaphragm causing shallowing of the anterior chamber and subsequent elevated intraocular pressure. As mentioned by Dr. Shubhakaran, OCT of the anterior segment demonstrates shallowing of the anterior chamber and conventional retinal OCT can show choroidal thickening as early as 1 week after starting topiramate therapy. ${ }^{5}$ These anatomical changes can occur without producing any ocular symptoms but certainly increase the risk of developing unilateral or even bilateral acute angle closure glaucoma in patients with asymptomatic narrow angles. ${ }^{6}$ It would be prudent to consult with an ophthalmologist to evaluate for narrow angles before initiating therapy and utilizing OCT to monitor subclinical ocular changes at 1 week after the start of therapy. However, we would like to emphasize that topiramate-induced glaucoma is a clinical diagnosis and requires measuring intraocular pressure.

Duke University, Durham, NC.

Disclosures: R.S. Maldonado and P. Mettu report no disclosures. M. El-Dairi serves as a consultant for Prana Biotechnology and receives research support from The Knights Templar. M. Bhatti has received funding for travel from and serves on a scientific advisory board, as a consultant, and on the speakers' bureaus for Novartis and serves on the editorial board of Journal of Neuro-Ophthalmology.

Correspondence to: tariq.bhatti@duke.edu

1. Maldonado RS, Mettu P, El-Dairi M, Bhatti MT. The application of optical coherence tomography in neurologic diseases. Neurol Clin Pract 2015;5:460-469.

2. Adhi M. Optical coherence tomography: current and future applications. Curr Opin Ophthalmol 2013;24:213-221.

3. Mitra A, Ramakrishnan R, Kader MA. Anterior segment optical coherence tomography documentation of a case of topiramate induced acute angle closure. Indian J Ophthalmol 2014;62:619-622.

4. Shubhakaran KP. Anterior segment optical coherence tomography in angle closure glaucoma with topiramate use. Indian J Ophthalmol 2014;62:1174-1175.

5. Karalezli A, Koktekir BE, Celik G. Topiramate-induced changes in anterior chamber angle and choroidal thickness. Eye Contact Lens Epub 2015 May 23

6. Palomares P, Amselem L, Diaz-Llopis M. Optical coherence tomography for diagnosis and monitoring of angle-closure glaucoma induced by topiramate. Can J Ophthalmol 2007;42:633-634.

\section{Neurology ${ }^{\circledR}$ Genetics Call For Papers}

Neurology"

*

Genetics

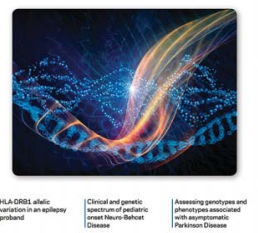

Neurology: Genetics is an open access, online only journal that will provide neurologists with outstanding original contributions that elucidate the role of genetic and epigenetic variation in diseases and biological traits of the central and peripheral nervous system. We welcome all submissions. For more information on how to submit, visit http://www.neurology.org/site/ $\equiv$ gen/gen2.xhtml. 


\title{
Neurology ${ }^{\circ}$ Clinical Practice
}

\author{
Evaluating persistent altered mental status after status epilepticus \\ Nitin K. Sethi and Stephen Hantus \\ Neurol Clin Pract 2016;6;8-9 \\ DOI 10.1212/01.CPJ.0000481032.17694.ab
}

This information is current as of February 15, 2016

Updated Information \&
Services
References
Permissions \& Licensing
Reprints

Updated Information \&

References

Reprints including high resolution figures, can be found at:

http://cp.neurology.org/content/6/1/8.2.full.html

This article cites 2 articles, 1 of which you can access for free at: http://cp.neurology.org/content/6/1/8.2.full.html\#\#ref-list-1

Information about reproducing this article in parts (figures,tables) or in its entirety can be found online at:

http://cp.neurology.org/misc/about.xhtml\#permissions

Information about ordering reprints can be found online:

http://cp.neurology.org/misc/addir.xhtml\#reprintsus

Neurol Clin Pract is an official journal of the American Academy of Neurology. Published continuously since 2011, it is now a bimonthly with 6 issues per year. Copyright (C) 2016 American Academy of Neurology. All rights reserved. Print ISSN: 2163-0402. Online ISSN: 2163-0933.

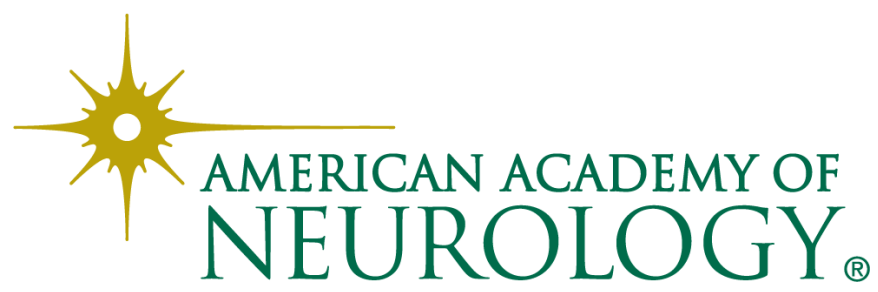

